\title{
Imitação e emulação nas letras luso-brasileiras: Francisco Rodrigues Lobo, Gregório de Matos e Guerra e Tomás Pinto Brandão
}

\author{
Marcello Moreira'
}

\begin{abstract}
RESUMO: O artigo tem como objetivo analisar as relações entre dois princípios que estão na base do fazer poético dos séculos XVI e XVII, "imitação" e "emulação". No que concerne ao primeiro deles, lê-se novamente a Poética de Aristóteles com a finalidade de demonstrar que a mimese, conquanto seja imitação de ação, é, sobretudo, imitação de afecções ou de estados patéticos. A voz que enuncia, nos vários gêneros poéticos, não é a do indivíduo poeta, mas a de uma persona que finge estados patéticos. Leitores dos poemas nos dias de hoje creem haver "expressão" ou "sinceridade" no que leem, sem se aperceberem de que tudo é efeito da aplicação de técnicas discursivas, gramaticais, poéticas e retóricas. A emulação, como reconhecimento de carência e desejo de superá-la, é emulação principalmente do que é mais excelente, ou seja, de caracteres e seus feitos; em poesia, é tentativa de imitação e superação de discursos modelares, apropriação, por conseguinte, de estados patéticos já figurados de acordo com convenções de gênero. A emulação é imitação de imitação e é esse caráter produtivo da mimese aristotélica nos séculos XVI e XVII que tentaremos tornar evidente neste estudo.
\end{abstract}

PALAVRAS-CHAVE: Imitação; emulação; poética; retórica; poesia luso-brasileira.

1. Agradecemos ao $\mathrm{CNPq}$ a concessão de bolsa de produtividade em pesquisa, $\mathrm{PQ}$, que financiou esta pesquisa. 
ABSTRACT: The objective of this study was to analyze the relationships between two principles (imitation and emulation) that were the basis of creating poetry during the $16^{\text {th }}$ and $17^{\text {th }}$ Centuries. Concerning the former, we undertake a new reading of Aristotle's Poetics with the intention of demonstrating that mimesis, when it is the imitation of action, is above all the imitation of affect and/or pathos. In poetic genres, the declarative voice is not that of an individual poet but that of a persona feigning pathos. Today's readers of poems believe there is "expressiveness" or "sincerity" in what they read, without perceiving that all of it is affected by the application of discursive, grammatical, poetic, and rhetorical techniques. Emulation, as recognition of a need and the desire to overcome it, is the emulation principally of that which is most excellent, or rather, of the characters and their deeds; in poetry, it is an attempt to imitate and supersede model discourses; appropriation, thus, of states of pathos that already figure in their agreement with the conventions of the genre. We attempt to make evident in the present study that emulation is the imitation of imitation and is the productive character of Aristotelian mimesis of the $16^{\text {th }}$ and $17^{\text {th }}$ Centuries.

KEYWORDS: Imitation; emulation; poetics; rhetoric; Luso-Brazilian poetry. 
Pode-se aqui apresentar uma hipótese de trabalho, a ser verificada ulteriormente, mas não necessariamente neste estudo: se há distinção, proposta pelos próprios preceptistas, entre, de um lado, preceptiva ou arte, e, de outro, "execução" (esecutione), "operação" (operatione) e costume (habito), ${ }^{2}$ tem-se de pensar a emulação como operação que articula princípios doutrinais, dispersos nos tratados, e matrizes ou modelos, em que já se efetuou essa operação; a cada nova emulação de um poema, portanto, cada poeta pode atualizar corpos de doutrina distintos do que regra seu modelo, o que produz fraturas acumuladas no costume, sempre dinâmico, de um dado gênero. Desse modo, a operação de articulação entre corpos de doutrina e modelo, efetuada em um dado poema, é novamente operada quando da composição de uma emulação e, assim como se pode pensar o que se apropria por viés distinto do ponto de vista preceptivo, pode-se também atualizar o modelo pensando-se em seus modelos ou em emulações do mesmo modelo que concorrem com ela, o que parece produzir reflexos que espelham reflexos ou espelhos que refletem outros espelhos, sendo a ordem dominante do discurso poético prismástica, porque não plana: um poema não é figura, mas poliedro. Se o poeta é distinto do preceptista, porque é o que executa o preceito (eseguente), não o que o ensina (insegnante), só pode, no entanto, executá-lo à medida que já se tornou mestre de seu ofício pela compreensão e memória dos corpos de doutrina e modelos que regram seu saber fazer.

\section{II}

Aristóteles, na Retórica, apresenta-nos a mais antiga definição de emulação que se conhece no âmbito das artes do discurso e nela não há referência à poesia, cabendo ao estudioso relacioná-la com o que se entende como aemulatio no campo geral da poiesis. Quando na Retórica se fala de emulação, ela não concerne de imediato ao discurso: a emulação respeita à carência e ao apetite. Ela sempre se dá quando, diante de bens, quaisquer que sejam, que pertencem a outrem que faz jus a eles, e que é como o que os deseja - não estando o que se encontra deles privado, impossibilitado de os ter por estar muito abaixo do possessor -, este, o carente, experimenta um afeto doloroso. A sensação dolorosa não é

2. Piccolomini, Alessandro. Annotationi di M. Alessandro Piccolomini, nel Libro della Poetica d'Aristotile; con la tradutione del medesimo Libro, in lingua Volgare. Vinegia: 1572, sem numeração de página no original. 
ocasionada por outrem ter o que tem. O que move o emulador não é, segundo Aristóteles, uma paixão baixa, como, por exemplo, a inveja; o emulador sabe apenas que, desprovido do que poderia ter, anseia por tê-lo para eliminar o afeto que lhe é doloroso. ${ }^{3} \mathrm{~A}$ emulação, por conseguinte, move sempre um carente a desempenhar-se para obter o que lhe falta e é móvel de ação; ela sempre é virtuosa e característica de homens dotados de altas virtudes, opondo-se ao vício e a tudo o que lhe é inerente: não se deve, portanto, confundir emulação com inveja, ou ainda com cobiça, porque ela não é desejo sôfrego de se ter de qualquer maneira o que se deseja, o que faz o cobiçoso, que é desarrazoado; além do mais, o êmulo, para obter o que lhe falta, não apenas age justamente, mas torna-se industrioso para suprir sua carência, ao contrário do invejoso, que quer tudo para si, enquanto maquina meios de prevenir que outro venha a ter o que ele quer com exclusividade $\mathrm{e}^{4}$ simultâneo prejuízo de outrem. Dentre todos os bens que se podem almejar, alguns são mais desejáveis do que outros, e o são não só porque são valiosos por si, mas porque são normalmente considerados como próprios de homens honrados e virtuosos: as honrarias civis, os cargos públicos, grande número de amigos qualificados, riqueza advinda da família ou conquistada de forma merecida, como prêmio por serviços, tudo isso é estímulo aos que emulam mais o caráter dos seus possessores do que aquilo que possuem. $\mathrm{O}$ possuído vale justamente porque indicia a natureza moral do possuidor. Nesse sentido, a emulação passa a ser afeto doloroso, mas o é não porque há carência apenas de bens que se deseja possuir, mas sim porque há outra, mais difícil de suprir, e que implica empenho na superação de deficiências do próprio caráter, que, a despeito delas, reconhece-as para tornar-se em seguida apto a superá-las. Honradez possuída por ancestrais, por amigos, pela nação e pela cidade onde se nasceu, tudo isso move os homens virtuosos a emular, porque, segundo Aristóteles, eles pensam que essa honradez também lhes é devida e que não fazer jus a ela é declarar-se de certa forma indigno e aquém dos que a possuíram. ${ }^{5} \mathrm{~A}$ emulação das virtudes torna-se desse modo a emulação por excelência, porque se pode dizer que todos os outros bens podem ser conquistados pelo homem virtuoso e não há coisa que se deva mais ansiar por ter do que sabedoria, prudência, coragem e autoridade advinda do mérito; os virtuosos, que são por todos admirados, são por seu turno não apenas objeto de emulação, mas sobretudo de elogio, porque oradores e poetas tomam

3. ARISTOTLE. Art of Rhetoric. Cambridge: Harvard University Press, Loeb Classical Library, 1994, p. 243.

4. Ibidem.

5. Ibidem. 
como matéria de seu louvor homens excelentes por todo tipo de virtude: a memória da virtude, efetuada pelas artes do discurso, como poesia e oratória, estimula ainda mais o emulador a emular, porque, segundo o Estagirita, deseja mais do que tudo o bem de ter posteridade e fama. ${ }^{6}$ Poetas e oradores, por seu turno, ao tomarem como matéria de sua arte a virtude e os virtuosos, encarecendo-lhes feitos e caráter, tornando-os memória por meio da poesia e da oratória, efetuam sua própria virtude cívica ao reconhecerem e publicarem a virtude de outrem. É neste ponto que a Poética imbrica com a Retórica. Na Poética, Aristóteles assevera que a poesia imita caracteres em ação, e eles se diferenciam uns dos outros ou pela virtude que os anima, ou pelo vício que os espicaça a agir, havendo os que são como nós, os que excelem pela virtude, sendo melhores do que nós, e os que estão dominados pelo vício, sendo piores do que nós; ${ }^{7}$ a imitação caracterial é o cerne também da mimesis pictórica, e assim como há poetas que imitaram caracteres melhores do que nós (Homero tomou-os para si em seus dois grandes poemas), piores do que nós (Hegemão de Tasos, o primeiro compositor de paródias, e Nicócares, autor da Deilíada, ativeram-se a eles), ou ainda como nós (matéria da poesia de Cleofão), ${ }^{8}$ assim também houve pintores que preferiram imitar caracteres superiores (Polignoto), inferiores (Pausão) e como nós (Dionísio). ${ }^{9}$ Conquanto o poeta possa imitar o que imita de modos distintos, porque pode com o mesmo meio combinar narrativa e discurso direto, sem mediação do narrador, ou ainda valer-se exclusivamente da narração, ou pode ainda fazer uso somente do discurso direto, característico do drama, ${ }^{10} \mathrm{o}$ que há na base da imitação é ação, mas são também caracteres, o que torna o ethos elemento central em qualquer reflexão posterior sobre imitação, como se verá adiante. O ethos torna-se elemento axial de gêneros pictóricos, como o retrato, nos séculos XVI e XVII, em que expressão facial, evidência da caracterização pelo patético que articula a configuração, alia-se ao restante do corpo, falante em sua mudez, sobretudo quando vestido de sua segunda pele, a roupa. No retrato não há propriamente ação, mas a potência derivada do ânimo. No retrato dá-se a máxima modelização da corporeidade do corpo, porque nele não há ação ou narrativa,

\footnotetext{
6. Idem, p. 245.

7. Aristotle. Poetics. Edited and translated by Stephen Halliwell. Cambridge: Harvard University Press, Loeb Classical Library, 1995, pp. 1-142 [p. 33].

8. Idem, p. 35 .

9. Idem, p. 33 .

10. Idem, p. 35 .
} 
conquanto se possa dizer que as doutrinas sobre a representação do corpo cinético no drama ou do corpo em stasis no retrato já se fizessem presentes em preceptivas como a Retórica e a Poética, ao tratar-se da relação entre orador e actio e entre ator e performance. Aristóteles, ao falar da relação entre imitação e pintura, na Poética, afirma que "gostamos de contemplar a mais precisa imagem das coisas, mesmo daquelas cuja vista real nos causa repulsa", como cadáveres; ${ }^{11}$ e completa a asserção prévia ao dizer que "os homens gostam de olhar imagens porque por meio de sua contemplação eles entendem o que cada elemento constituinte significa, e podem, por exemplo, dizer 'essa pessoa é assim e assim"'. ${ }^{12} \mathrm{O}$ que isso significa exatamente? Como se pode dizer, pela pintura, pelo retrato, que uma pessoa seja assim e assim?

Aby Warburg, impactado pela teoria evolucionista de Charles Darwin, tentou compreender a "transmissão filogenética das condutas e das expressões faciais nos animais superiores e no homem"; por meio da combinação da teoria darwiniana e do conceito de "memória" emprestado da psicologia fenomenológica de princípios do século xx, propôs que nas artes representativas, como pintura e escultura, a expressão de estados patéticos poderia ser remontada à noção de "engrama": "conjunto estável e reforçado de marcas que determinados estímulos externos imprimiram na psique e que produz respostas automatizadas quando da reaparição desses mesmos estímulos".13 As expressões patéticas, presentes nas artes da representação desde gregos e romanos e recicladas nas artes europeias dos séculos XV, XVI e XVII, não poderiam, segundo Aby Warburg, ser compreendidas como meros costumes artísticos, como resultante de corpos de doutrina e preceituação. ${ }^{14} \mathrm{O}$ que importa por ora salientar é justamente como a apropriação dos engramas, o que implica sua interpretação modelizadora e consequente representação, fruto de uma técnica artística que se torna costumeira, pode ser estudada no âmbito de doutrinas fundadas na mimesis: é necessário levar a termo uma análise da Poética, da Retórica e da Ética a Nicômaco, de Aristóteles, para além das muitas apropriações que houve delas nos séculos XVI e XVII, com o objetivo de entender a relação entre representação e caracteres agentes,

11. Idem, p. 37.

12. Idem, p. 39.

13. BURUCÚA, José Emilio. Historia, arte, cultura. De Aby Warburg a Carlo Ginzburg. Buenos Aires: Fondo de Cultura Económica, 2005, p. 28.

14. WARBURG, Aby. El renascimiento del paganismo. Aportaciones a la historia cultural del Renascimiento europeo. Madrid: Alianza, 2005. 
de um lado, e, de outro, como na própria ideia de caracteres (drontes, agentes do drama), de base ética, está implicada uma poética caracterial da face, do corpo em ação, e uma retórica das afecções corporais. Se os engramas já modelizados por artes como poética e retórica são formas sociais partilhadas de cognição, que possibilitam, pelo conhecimento do traço patético correspondente à afecção que o ocasionou, o reconhecimento do pathos expresso como "expressão", porque já formalizado de acordo com convenções de gênero, estilo e decoro, seria nele, no engrama, que precisaria manter-se radicada toda representação para provocar no espectador a resposta biológica que se tem frente a um mesmo estímulo? Heinrich Wölfflin acreditava que, em termos estilísticos, o efeito de quadros sobre quadros era mais relevante do que a adesão à natureza propriamente dita ("the effect of picture on picture as a factor of style is much more important than that comes directly from the imitation of nature"). ${ }^{15}$ Ernst Gombrich também declara que a imitação de matrizes artísticas é mais relevante do que a empiria. ${ }^{16}$ Pode-se dizer que nos séculos XVI e XVII várias artes, como a escultura sacra e a pregação, tinham como uma de suas finalidades não apenas manter viva a memória dos engramas já modelizados, mas encontrar meios de produzir a intensificação de respostas passionais à inscrição desses engramas por meio da amplificação dos recursos artísticos que operavam sua representação. Seria equívoco histórico afirmar que toda escultura sacra e toda pregação visaram a essas intensificação e amplificação. O que importa por ora salientar é que as artes nos séculos XVI e XVII carecem de unidade e não devem ser sobredeterminadas por nenhuma etiqueta que a pressuponha, seja ela a de "Barroco" ou aquela de Kunstwollen, por exemplo. Não há diferença significativa entre propor uma unidade artística fundada em procedimento possível da elocução, como a agudeza, declarando-se que toda poesia portuguesa do século XVII é aguda e declarar ser essa mesma poesia do século XVII conceptista ou cultista; a unidade pressupõe em um caso como no outro o Wollen de uma época, e a necessária Weltanschauung que o possibilita, porque haveria "princípios estruturais prevalecentes", como dizia Riegl, em todos os fenômenos artísticos. ${ }^{17} \mathrm{O}$ que a modelização significa, sobretudo, é que a resposta a uma dada afecção, quando modelizada, torna-se objeto de um distinguo que é fruto do procedimento de notação. É somente porque o pintor e

\footnotetext{
15. WÖlfllin, Heinrich. Principles of Art History. New York: Dover, 1950, p. 250.

16. GOMBrich, Ernst. Art and Illusion. A Study in the Psychology of Pictorial Representation. Princeton: Princeton University Press, 1989.

17. PANOFSKy, Erwin. Perspective as Symbolic Form. New York: Zone Books, 1991, p. 8.
} 
também o poeta são capazes de anotar, prática essa que gera um capital de anotações que constituem cumulativamente um costume, é que somos capazes de dizer, frente a uma pintura ou a uma escultura, "essa pessoa é assim e assim". Essa distinção fruto da pragmática da anotação já fora percebida e analisada há anos por João Adolfo Hansen, em seu conhecidíssimo $A$ sátira e o engenho, quando, ao discorrer sobre a prática de composição da poesia satírica na Bahia do século XVII, assevera que é pelo olho da persona satírica

que os pontos focalizados assumem a identidade genérica de tipos reconhecíveis [...]: chim, brâmane, judeu, negro, mulato, índio, mameluco, mazombo, turco, muçulmano, fidalgo, luterano, freira, padre, soldado, puta, dama, marido cornudo, sodomita etc. Subdividindo seu elenco, o olho infla os caracteres, faz distinções meticulosas entre sagrado e profano, puro e impuro, legítimo e bastardo. ${ }^{18}$

III

Os que pintam caracteres melhores do que nós estimulam-nos a emulá-los para que nossa imagem também possa ser legada, como a deles, à posteridade ${ }^{19}$ mas os que pintam tipos viciosos, ou os que tomam os que são piores do que nós como matéria de seu poetar, se o fazem para castigar o vício e propor a correção da desordem, também agem civilmente e em benefício da república. Desse modo, agem virtuosamente ao representar o vício. Se os emuladores desejam emular os que são dotados de virtude e que prestam grandes serviços aos outros homens, há-os poucos, melhores do que poetas e oradores. Mas o que se emula, quando se emulam poeta e orador? Não são emulados justamente no que são mais virtuosos, ou seja, na sua capacidade de, ao imitar toda sorte de caracteres, estimular-nos à virtude e à rejeição do vício? Mas como se emula o que excele por saber imitar? William Kennedy, em seu conhecido Rhetorical Criticism, ${ }^{20}$ ao falar da disjunção que pode haver entre o autor empírico e a voz ficta que articula a poesia, assevera que nenhum "papel" desempenhado pelo autor equivale à sua inteira "natureza ficta", já que "o autor representa vários papéis, alguns complementares, outros contrastantes”. O que quer isso dizer? Que

18. HAnsen, João Adolfo. A sátira e o engenho. Gregório de Matos e a Bahia do século XVII. São Paulo: Ateliê Editorial; Campinas: Editora da Unicamp, 2004, p. 197.

19. Alberti. Leon Battista. Da pintura. 4 ed. Campinas: Editora da Unicamp, 2014.

20. Kennedy, William. Rhetorical Criticism and Literary Theory. New Haven: Yale University Press, 1978.

44 - MOREIRA, Marcello. Imitação e emulação nas letras luso-brasileiras 
o autor, podendo, a depender do gênero que produz, encenar uma persona própria do gênero praticado, e como, em teoria, pode encenar qualquer persona, mesmo aquelas que nunca encenou, todas as vozes que encenou não equivalem à potência de seu vir a ser? Não cremos que William Kennedy tenha se proposto tal reflexão, porque diz que toda a poesia escrita por um dado autor é falha como expressão de "sua essência moral", ${ }^{21}$ o que parece rearticular, por mais paradoxal que isso nos pareça, a prática de composição de discursos sempre pensados genericamente - com seu aptum em termos inventivos, dispositivos e elocutivos -, com a personalidade, e, por conseguinte, com o autor empírico. William Kennedy reconhece que a voz que articula a poesia, em seus vários gêneros constitutivos, é persona, e, nesse sentido, não pode equivaler ao autor empírico, mas, ao mesmo tempo, ao interpretar poesia como expressão, esforça-se por compreender como a poesia é fruto de um self, anterior à ficção da voz da persona. Esta é de fundamental importância para se entender o procedimento da mimesis: João Adolfo Hansen, em $A$ sátira e o engenho, ao tratar de forma minudenciada da sátira e dos corpos de doutrina que a regravam no século XVII, assevera que a persona ou voz ficta desse gênero, fruto ela própria de uma pragmática, "compõe inúmeros ilegalismos, formalizando-os exemplarmente", e que, entre eles, destaca-se o ilegalismo "da persona satírica, cujo olhar desce no vício, estilo baixo das paixões, para subir em virtude, estilo alto de seu juízo";22 mais, a própria formalização do vício figura a "compatibilidade entre as interpretações dos temas feitas pelos personagens satíricos em ato e os atos da interpretação dos poemas pelas recepções empíricas diferenciadas, que conferem valor e sentido à representação". ${ }^{23}$ Se se pode dizer que a sátira é prática discursiva de notação de vício por meio de "sistema simbólico convencional de preceitos técnicos, verossimilhanças e decoros partilhados por sujeitos da enunciação, destinatários e públicos empíricos”, ${ }^{24} \mathrm{o}$ anotar, que formaliza, $\mathrm{o}$ faz não só frente à sua matéria, mas ainda mais face ao sujeito de sua enunciação, a persona, como também frente ao auditório, que, antes de ser empírico, o é como resultante ou efeito da aplicação dos mesmos preceitos técnicos, verossimilhanças e decoros, e, nesse sentido, é tão ficto quanto a persona e também como a matéria. Esta é particularizada, na sátira atribuída, por exemplo, a Gregório de Matos e Guerra, pela anteposição de didascálias aos poemas,

\footnotetext{
21. Idem, p. 4.

22. HANSEN, João Adolfo. Op. cit., 2004, p. 193.

23. Idem. "Pedra e cal: freiráticos na sátira luso-brasileira". Revista usP, n. 57, pp. 68-85, mar./maio, 2003, p. 69. 24. Ibidem.
} 
que encenam a "ausência" de lugar, tempo e pessoa como presença ficta, evidenciada por procedimento dêitico: a persona aponta, indicia a matéria de seu falar; em cópia inscrita em outro códice da tradição de Gregório de Matos e Guerra, contudo, o poema muita vez, não sendo completamente idêntico a si mesmo, já que há nele incontáveis variantes adiáforas, torna-se radicalmente outro porque outra é sua matéria, como somos informados por sua novíssima didascália, ${ }^{25} \mathrm{em}$ que outros são lugar, tempo e pessoa. A mimesis, enquanto técnica, no entanto, é aplicável a todas as variantes. Ela diz respeito não só à invenção, mas à disposição e à elocução, desde a selectio verborum até à escolha de tropos e figuras, com o uso de elencos de topoi de todos os gêneros. William Kennedy, ao estudar o soneto petrarquista, demonstrou cabalmente que ele implica não apenas uma matéria ou um argumento, mas disposição e elocução garantidas pelo costume, o que permite, inclusive, que se fale de uma tradição petrarquista própria desse gênero na Europa dos séculos XV, XVI e XVII. ${ }^{26}$ A disposição da matéria nas quatro estrofes que compõem o soneto geralmente produz a característica tensão do gênero, já que o discurso é articulado pelo balanço de tese e antítese, em que certeza e dúvida, alegria e tristeza, esperança e desespero são lugares comuníssimos desses balanço e articulação. O soneto em Petrarca é normalmente dividido em duas largas seções, a oitava e a sextilha, que se estruturam como oposição simétrica. ${ }^{27}$ O tratamento do argumento na oitava corresponde normalmente a tratamento contrastante na sextilha; é possível ainda que a matéria seja dividida por unidades discursivas ainda menores, como, por exemplo, a partição da oitava em dois quartetos, que rimam $a b b a$, ou a divisão da sextilha em dois tercetos, que rimam $c d e$, ou em três dísticos, que rimam $c d$; a estratégia de divisão e disposição da matéria, com suas articulações lógicas, prevê estruturas costumeiras como, por exemplo, "quadra-quadra-sexteto", ou "oitava-terceto-terceto", ou "quadra-quadra-terceto-terceto", ou "quadra-quadra-quadra-dístico", ou "quadra-quadra-dístico-quadra", ou ainda em formas ditas irregulares, em que há divisões em cinco ou seis partes: o que há em comum é que o último segmento sempre resolve o primeiro, tornando-se seu desfecho lógico ou remate..$^{28}$ Nesse sentido, a imitação implica

25. MOREIRA, Marcello. Critica textualis in caelum revocata? Uma proposta de edição e estudo da tradição de Gregório de Matos e Guerra. São Paulo: Edusp, 2011, sobretudo o capítulo IV.

26. Kennedy, William. Op. cit., p. 21. Ver ainda Dotti, Ugo Vida de Petrarca. Campinas: Editora da Unicamp, 2006.

27. Ibidem.

28. Idem, pp. 21-2. 
a ficção da persona, aquela da matéria em sua aparente singularidade ou caso, aquela do auditório a que a obra se remete enquanto discurso genérico, e o costume de divisão e disposição da matéria em sua articulação estrófica e versífica: a persona, para ser reconhecida como voz apropriadíssima em cada ocasião em que fala, só pode fazê-lo atendendo a usos costumeiros, autorizados por pragmáticas sancionadas social e culturalmente. Nesse sentido, a notação, ao notar, fá-lo pensando-se simultaneamente como divisão e disposição da matéria. Como já dissemos, a imitação, segundo estudiosos como Ernst Gombrich e Heinrich Wölfflin, é procedimento muito mais calcado na atualização de modelos do que na observação da natureza, no que concerne à arte da pintura; em poesia, a imitação, ao ser pensada como emulação ou concorrência por excelência, pelo reconhecimento do exceler dos modelos que se deseja pelo menos igualar, pode ser pensada a partir do que João Adolfo Hansen pensou como princípio de composição da sátira: a operação de composição sempre pensa ao mesmo tempo um "notável" e o expõe, sendo a exposição espécie de amplificação que no-lo dá como "anotado", em que se corrige o notado; ${ }^{29}$ a correção é devida à perspicuidade da persona, que, em cada gênero praticado, penetra na natureza discreta de vícios e virtudes, patenteando-lhes valor e falta, o que não penetra a rusticidade de muitos. Todas as operações poéticas são ordenadas por um notandum, que respeita não apenas o que se nota e como se o nota, mas também a divisão e disposição do notado e em seguida anotado.

\section{IV}

A imitação como operação que tem como objeto "caracteres agentes" é central na tradição reflexiva que tomou para si a poesia nos séculos XVI e XviI. Parece, quando lemos muitas preceptivas poéticas italianas e francesas desse tempo, que sempre nos deparamos com definições de poesia em que imitação de ação é nuclear para a reflexão poética. Bernardino Daniello, por exemplo, define poesia como imitação de ação, ${ }^{30}$ mas é apenas um dos muitos tratadistas que, após reconhecer ser a mimesis própria do gênero dramático - não se esquecendo, contudo, de gêneros mistos, como o poema heroico, em que se misturam imitação e narração -, principia em seguida a declarar que poemas que

29. HANSEN, João Adolfo. Op. cit., 2004, p. 195.

30. DAniello, Bernardino. Della Poetica di Bernardino Daniello Lucchese á Monsignore Messer Andrea Cornelio Eletto Vescovo di Brescia Suo Signore. G. di Nicoloni da Sabio, 1536. 
têm como matéria a passagem do tempo, descrevendo-a, ou que tomam como objeto do poetar o verdor dos campos, a beleza primaveril, uma montanha, um vale, um passarinho etc., não são poesia propriamente dita, pois nada imitam, ou seja, são desprovidos de ação e não se atêm a nenhum caráter agente. Há outros preceptistas, que, como Bernardino Daniello, excluem o que chamamos hoje em dia de lírica do universo da poesia, embora não deem nome àquilo que excluem da poética por seu caráter justamente apoético. Se sonetos, canções e epigramas, por exemplo, não são poesia, são o quê? Outro grande tratadista da arte poética do século XVI, Alessandro Piccolomini, em suas anotações à Poética de Aristóteles, concorda com Bernardino Daniello ao ler o livro aristotélico como fundamento para qualquer reflexão pertinente sobre a poesia. Nelas, assevera que muitos pensam que, desde que se imite algo, haverá poesia, por haver imitação; em um importante fragmento em que se propõe circunscrever o sentido do poético como resultante de uma operação mimética, assevera que, caso desejemos "descrever e definir, o mais exatamente que possamos, a Poesia, devemos então dizer que ela não seja outra coisa que imitação, não só de coisas naturais ou artificiais, mas sobretudo de ações, costumes e afetos humanos, levada a termo por meio do falar, ou verdadeiramente da locução no que tem de universal, a fim de deleitar, e, deleitando, ocasionar prazer à vida humana":

se la vogliamo esattamente, che noi potiamo, descriuere, \& difinire, dobbiam dire, che la Poesia non sia altro, che imitatione, non solo di cose, ò naturali, ò artificiose; ma principalmente dattioni, di costumi, \& daffetti humani: fatta col mezzo principalmente del parlare, ò ver della locutione nel lor uniuersale, à fine di dilletare, \& dilletando finalmente giouare alla uita humana. ${ }^{31}$

O que significa imitação de ações, costumes e afetos humanos é coisa claríssima a leitores da Poética, mas o que seria, por outro lado, "imitação de coisa natural, ou artificial"? Um pouco à frente, Alessandro Piccolomini produz uma nova circunscrição do fenômeno poético; nessa circunscrição, define claramente o que entende por "imitação de coisas naturais e artificiais", mas, ao fazê-lo, acaba por chegar à conclusão, sempre com base na Poética de Aristóteles, de que a imitação de coisas naturais e artificiais nem sempre é "poética". Alessandro Piccolomini defende a seguinte interpretação do livro do Estagirita: a imitação que define o poético enquanto poético é imitação particularíssima, pois é sempre "imita-

31. PICCOLOMINI, Alessandro. Op. cit., 1572, sem numeração de página no original. 
ção de ações de homens", havendo pequena concessão à imitação de afetos: nesse sentido, embora haja "poemas", segundo alguns os chamam, que têm como matéria o anoitecer, o amanhecer - aqui, Alessandro Piccolomini fala de coisas naturais e remete, neste último exemplo, seu leitor ao tradicional gênero lírico denominado pelos estudiosos da poesia medieval "alba" -, a inundação ocasionada por um rio, a chegada da primavera, ou que descrevem coisas como um palácio, uma cidade, um templo e outras coisas "artificiosas", tudo isso não é propriamente poesia, pois nesses "poemas" não há ação imitada ou caracteres agentes e seus estados patéticos ocasionados pelas mais diversas afecções da alma:

Per mostrare, che non basta à far essere una imitation poesia, che solamente s'imiti una cosa, ò naturale, ò artificiale; se la imitatione di tai cose non seruono, ò non s'indrizzono allimitatione di qualchattione dell'huomo, di maneira che qualunche imitasse, ò descriuesse nel suo parlare un farsi notte, un farsi giorno, ò una inondazione d'un fiume, ò la venuta della primavera, ò altra cosa naturale; ò ueramente imitasse, \& descriuesse un palazzo, una Città, un Tempio, ò altra artifitios a cosa; \& in cosi fatte imitationi si finisse, \& si terminasse, senza inferirle, \& applicarle, \& farle seruir allimitatione propriamente, \& legittimamente attribuir à se il vero nome di poesia: ma solo impropriamente; comiaccade in alcuni Epigrammi alle volte; $o$ in alcuni Sonetti, ò in altri simili componimenti, che propriissimamente connumerar non si deono frà le legitime spetie della poesia. ${ }^{32}$

Poder-se-ia pensar que a exclusão de parte significativa da lírica do campo do poético seria um passo extremado dado por alguns comentaristas da Poética de Aristóteles, mas, a partir da conclusão a que chega, por exemplo, Alessandro Piccolomini, pode-se ainda ir um pouco "adiante" na interpretação da Poética e do fenômeno poético que ela se propõe elucidar. Dessa recusa do poético a alguns gêneros de "poesia" então praticados para uma completa denegação da imitação como núcleo duro definidor da poiesis é apenas um átimo, e, embora não o vejamos em quase nenhum escrito, encontramo-lo no Poetices Libri Septem, de Escalígero, publicado em 1561. O livro de Escalígero é anterior ao de Alessandro Piccolomini, mas posterior ao de Bernardino Daniello, em que se encontram as mesmas ideias de que tratamos ao citar Alessandro Piccolomini, o que demonstra a falta de unidade doutrinária no campo dos estudos poéticos e a colisão de posições interpretativas da Poética, a ponto de não se poder reduzir esse capital de

32. PICCOLOMINI, Alessandro. Op. cit., 1572, sem numeração de página no original. 
comentários e posições interpretativas a uma unidade "teórica" qualquer. Escalígero choca-nos nos dias de hoje mais do que Alessandro Piccolomini, porque seu livro, não mais lido, e de que ignoramos quase tudo, apresenta-nos uma declaração contrária a quase toda a tradição doutrinária de reflexão sobre o poético, que tinha justamente na Poética aristotélica, a par da Epistola ad Pisones, de Horácio, sua arché. Em Poetices Libri Septem Escalígero afirma, contrariando boa parte de seus contemporâneos, que:

poesia não é imitação, porque nem todo poema é imitação e nem todo homem que imita pode ser chamado poeta; a poesia também não se caracteriza por ser coisa ficta ou mentirosa, pois a poesia não mente, e, se mente, é apenas um tipo de poesia, mas não poesia em geral; por fim, há imitação em toda a linguagem, pois a palavra é imagem das coisas. A finalidade da poesia é ensinar com deleite. ${ }^{33}$

Vejamos: a poesia, segundo Escalígero, não deve ser definida como imitação, porque há poesia que não imita, a despeito de ainda assim ser poesia. Essa é uma "pequena torsão" na interpretação da Poética realizada por tratadistas como Bernardino Daniello e Alessandro Piccolomini: estes últimos dizem que gêneros líricos como soneto, canção e epigrama, ao não imitarem ação, ou descrições, por não imitarem nem ações nem afetos, não são propriamente poesia, o que permite a Escalígero concluir que eles, os gêneros líricos em geral, são sim poesia, porque não é a imitação de ação ou de afeto o que define poesia enquanto tal; soneto, canção e epigrama, sendo poéticos, a despeito de não serem aristotelicamente "imitação", permitem-nos questionar a própria Poética: como diz Escalígero, Aristóteles está errado. A imitação de ação, que, como vimos, não define o poético da poesia, tem certa finalidade: "o poeta nos ensina a natureza dos caracteres quando os põe a praticar uma ação, faz com que desejemos imitar os bons e rejeitar os maus, o que redunda no agir conforme a uns e contrários a outros; a ação é, por conseguinte, um meio de ensinar e o caráter é aquilo que nos é ensinado". ${ }^{34}$ Toda poesia em que se mimetiza uma ação, nesse sentido, ensina-nos, mas Escalígero produz uma hierarquização da instrução proporcionada pela poesia, pois, se os poemas que representam ações cometidas

33. SCAligeri, Iulii Caesaris. Poetices Libri Septem. Lyon: Antonius Vicentius, 1561, pp. 346-7.

34. Idem. Op. cit., p. 348 ("Docet affectus poeta per actiones: vt bonos amplectamur, atque imitemur ad agendum: malos aspernemur ob abstinendum. Est igitur actio docendi modus: affectus, quem docemur ad agendum. quare erit actio quasi exemplar, aut instrumentum in fabula: affectus vero finis"). 
por caracteres viciosos só podem nos instruir sobre o que rejeitar, e rejeição não implica adesão, imitação, emulação e competência, aquelas empreendidas por caracteres virtuosos estimulam-nos justamente a aderir, imitar, emular e competir. Escalígero, em seu Poetices Libri Septem, afirma Bernard Weinberg, ao tratar dos verba, assevera que nada se pode dizer deles sem referência às res: para Bernard Weinberg, no sistema poético e retórico de Escalígero, dos dois elementos, verba e res, o segundo é sem sombra de dúvida o mais importante, ${ }^{35}$ e verba são de tal modo reflexão das res, que “estilos' são apropriados às coisas": "Os gêneros são distintos por aquilo que representam e são dispostos em uma hierarquia de excelência de acordo com a excelência de seus objetos". ${ }^{36}$

Mas como pode a poesia, segundo Escalígero, aquela que não o é de acordo com Bernardino Daniello e Alessandro Piccolomini, ensinar-nos, e, se nos ensina, ensina-nos o quê, se não trata por necessidade de virtude e vício, de adesão à virtude e de rejeição ao vício? Não encontramos em Escalígero resposta para essas perguntas, mas deparamo-nos com ela nos tratados que declaram que a lírica não é poesia por não ser exatamente imitativa: Alessandro Piccolomini, ao comentar sonetos e canções de Francesco Petrarca, aqueles que têm como matéria coisas naturais, como a chegada da primavera, o desabrochar e o fenecer de uma flor, por exemplo, diz-nos que devem ser lidos como metáfora de uma afecção do caráter que articula as palavras (parole), e, nesse sentido, seriam, caso pensemos em Escalígero e seu desejo de instrução pela poesia, finalidade dela, instrutivíssimos, porque nos ensinariam a falar do amor sublimado, próprio de gentes principais. Luís de Camões, por exemplo, em seu soneto "Num jardim adornado de verdura", retoma o tema do hortus, esmaltado por flores várias, para comparar rosa, lírio e viola; a primeira é tomada por Diana, o segundo, por Vênus, e a terceira, ainda sem mão que a arrebate, é considerada por Cupido superior às outras duas, figuração metafórica da persona, que se nos apresenta mais ajuizada do que as duas deusas, por saber melhor escolher, e viola, o que escolhe, é metáfora flórea homônima, que tensiona o $A$ ser $B$ e não ser ao mesmo tempo $B$. Se o soneto não tem como matéria uma ação, tem-na como afecção da persona. Caso nos recordemos de um outro poema de Luís de Camões, "Transforma-se o amador na cousa amada", ${ }^{37}$ torna-se patente que a persona, própria do soneto amatório, articula sua

35. Weinberg, Bernard. "Scaliger versus Aristotle on Poetics". In: Modern Philology, vol. 39, n. 4, May 1942, pp. 337-6o [p. 344].

36. Idem, p. 344.

37. CAmões, Luís de. Rimas de Luís de Camões. Accrescentadas nesta segunda impressão. Dirigida a 
"fala" como verba reflexos de uma res, e, ao assim operar a linguagem e a si mesmo como linguagem, "transforma-se [...] na cousa amada/ Por virtude do muito imaginar". A imitação que aqui se produz se não é de ação, é, com certeza, imitação de afecção, e, portanto, imitação caracterial, porque a persona sempre se nos apresenta como caráter, com sua lexis. Mas muitos sonetos de amor de Luís de Camões, se imitam uma afecção e a persona que os articula ao articular-se poeticamente como voz, só o fazem à medida que imitam uma persona já modelizada, evidente nos modelos do gênero praticado, possuidores de auctoritas; a imitação aqui deve ser compreendida como emulação, porque implica a adesão à virtus articulatória, gramatical, poética, retórica e discursiva, que estimula à competência; se se emula, emula-se o caráter, o do poeta, que excele civilmente ao falar de virtude e vício, distribuindo elogio e vitupério, e o das personae que ele finge, com suas vozes que atendem a cada gênero praticado. A emulação, nesse sentido, princípio ético, desdobra-se em prática no âmbito das artes do discurso, que na poética se conjuga inextricavelmente com imitação. No âmbito das práticas emulatórias e imitativas da poesia portuguesa dos séculos XVI e XVII, a atualização de modelo por meio de imitação/emulação pode conjugar no ato mais de um campo de doutrina sobre o gênero praticado e a concomitante atualidade no poema, fruto da emulação/imitação, de mais de um modelo, de que redundam inflexões de vária natureza. Como exemplo dessa interferência de corpos de doutrina uns sobre os outros e da conjugação de modelos poéticos, apresentamos aqui três sonetos portugueses, em que a prática da emulação/imitação é evidente, e que nos propomos analisar, mesmo que de modo propedêutico: "Fermoso Tejo meu, quão differente" (Francisco Rodrigues Lobo), “Triste Bahia! Ó quão dessemelhante” (Gregório de Matos e Guerra) e "Fermoza minha Sè, quão diferente" (Tomás Pinto Brandão). O soneto, no século XVII português, não é gênero que costumamos compreender em sua historicidade como ligado ainda à voz, à música e à performance, e pensamo-lo como fruto de uma operação eminentemente escriturária. Quando recompostos parcialmente nos manuscritos que no-los transmitiram, cremos que essas alterações são devidas a intervenções também elas radicadas na mão. Pensamos que essa crença na radicação do soneto na escritura tem de ser criticada com base na leitura de obras sobre a poética, compostas nos séculos XVI e XVII, e que nos subministram informação sobre uma relação mais intrínseca do que imaginamos sobre poesia e música, de que Francesco Patrizi é apenas um dos muito excelentes infor-

d. Gonçalo Coutinho. Lisboa: Pedro Crasbeck, 1598, p. 3. 
mantes de que dispomos para essas necessárias crítica e elucidação, ${ }^{38}$ que, no entanto, não são objeto deste estudo. $\mathrm{O}$ que se pode dizer, mesmo com restrição de nossa reflexão ao pensar o soneto como fruto de prática de escritura, é que esse gênero, ao ser emulado/ imitado, era-o com a retomada de base textual modelar, constituída de estruturas sintagmáticas e esquemas métricos, rítmicos e rímicos, como se houvesse mudança em nível de superfície, com concomitante manutenção de uma "ordem profunda". O soneto de Tomás Pinto Brandão, impresso em Pinto renascido, em 1732, "Fermoza minha Sè, quão diferente", é, como o declara a mesma didascália que o encima, emulação de poema atribuído a Francisco Rodrigues Lobo ("Fermoso Tejo meu, quão diferente"), tendo o soneto de Tomás Pinto Brandão seguido o de Francisco Rodrigues Lobo pelo atendimento aos "mesmos consoantes". A primeira quadra do soneto de Francisco Rodrigues Lobo principia por uma invocação "Fermoso Tejo meu”, que é a mesma que se encontra no soneto de Tomás Pinto Brandão "Fermoza minha Sè", com permuta daquilo que se invoca, Tejo/Sé, a que se segue a declaração de uma oposição entre o estado presente e o estado passado, do Tejo, no caso de Francisco Rodrigues Lobo, da Sé, naquele de Tomás Pinto Brandão, oposição marcada pela enargeia do verbo "ver", ora concernente à persona que enuncia (vejo/vi), ora ao que se invoca (vês/viste). O par verbal ver/ter visto implica a mudança no estado do que se vê, no passado, o que era claro, agora está turvo (Tejo), o que estava contente, ora está triste (persona): "Fermoso Tejo meu, quão diferente/ Te vejo e vi, me vês agora e viste:/ Turvo te vejo a ti, tu a mim triste,/ Claro te vi eu já, tu a mi contente". Tomás Pinto Brandão emula/ imita por réplica da estrutura sintagmática de base e em seu soneto lê-se a mesma sequência lexical do ponto de vista categorial, com mudança no nível da palavração: "Fermoza minha Sè, quão diferente,/ da Sè velha te ves, agora, e viste!/ Tu muy alegre estas, ella muy triste;/ ella com bem pezar, tu bem contente". Conquanto a emulação ao soneto de Francisco Rodrigues Lobo se estenda pelas quatro estrofes do poema de Tomás Pinto Brandão como se pode constatar pela leitura dos textos nos anexos -, com apropriação das suas estruturas sintagmáticas e réplica e com substituição pontual da palavração, o soneto de Francisco Rodrigues Lobo é uma vanitas e tem como matéria a caducidade da existência, enquanto o de Tomás Pinto Brandão é sátira. Na vanitas que ora lemos, a chegada da primavera promove a chamada renovatio mundi, que abarcará aquela do Tejo, mas, infelizmente, a persona da enunciação coloca-se fora de qualquer possibilidade de renovação, já

38. PATrizi, Francesco. Della Poetica di Francesco Patrici, La Deca Istoriale [...]. Ferrara: Vittorio Baldini, 1586 , pp. 4-5. 
que seu triste estado não mudará, o que altera a dinâmica de oposições entre tempos verbais que produz a enargeia desse poema. O soneto de Tomás Pinto Brandão, por outro lado, ao substituir Sé por Tejo, fala da caducidade não da vida, mas da velha Sé, infestada por cônegos que lhe tiram tudo ao invés de lhe acrescentar; a oposição se dá entre um outrora mais abundante e um presente de escassez, ocasionado pelo vício e pela corrupção que ele ocasiona. A mudança, a despeito da manutenção da estrutura linguageira do modelo, ocorre porque o gênero discursivo mudou, passando-se da poesia moral (vanitas) para a sátira (bomolochia). O poema atribuído a Gregório de Matos e Guerra permite justamente entender a mudança genérica da emulação entre os dois poemas anteriormente citados. No conhecido soneto do poeta baiano, há evidente apropriação do poema de Francisco Rodrigues Lobo, conquanto nele não haja uma quase réplica da palavração do soneto matricial; por outro lado, a manutenção de unidades lexicais, sobretudo em posição anafórica, a princípio de estrofe e verso, e a estabilidade do esquema rítmico e dos hemistíquios do modelo permitem identificar o texto do poeta português como texto emulado/imitado. No soneto atribuído a Gregório de Matos e Guerra, lastima-se e vitupera-se a Bahia por deixar-se chegar a tal estado de pobreza, resultante do acúmulo de práticas nocivas ao bem comum do Estado, fundadas em vícios não castigados. É no poema, dito de Gregório de Matos e Guerra, composto em estilo gravíssimo - o que era facultado pela própria preceptiva -, em consonância com a gravidade do modelo, que encontramos a transição entre vanitas/vitupério, manutenção concomitante do estilo alto do poema moral de Francisco Rodrigues Lobo, e invocação de sujeito assujeitado por viciosos, que corrompem a ordem pública, o que demanda a imediata intervenção do príncipe. Desse modo, a maledicência, em Gregório de Matos e Guerra, emula/imita, mas em gênero distinto, o grau elocutivo do soneto de Francisco Rodrigues Lobo; essa aparente "mistura" de matéria própria do vitupério, ou seja, o vício em geral, e elocução grave da vanitas, na verdade, não o é, porque, como lembro com João Adolfo Hansen, ${ }^{39}$ preceptivas poéticas nos séculos XVI e XVII autorizavam a gravitas e o tom admonitório e prudencial em poemas satíricos; como o poema de Tomás Pinto Brandão é maledicente e é ao mesmo tempo menos grave, tem-se de pensar que emula/imita mais de um modelo, já que conjugaria em uma única resultan-

39. Hansen, João Adolfo \& moreira, Marcello. Para que todos entendais. Poesia atribuída a Gregório de Matos e Guerra. Letrados, manuscritura, retórica, autoria, obra e público na Bahia dos séculos XVII e XVIII. Belo Horizonte/São Paulo: Autêntica/Programa de Pós-Graduação em Literatura Brasileira da FFLCH-USP-Capes, 2013. 
te a textualidade profunda do soneto de Francisco Rodrigues Lobo e também a bomolochia de Gregório de Matos e Guerra.

\section{SONETO DE TOMÁS PINTO BRANDÃO, 1732, P. 17}

A Sè Patriarcal pelos consoantes do Soneto, Fermozo Tejo meu, quão diferente.

Soneto 17

Fermoza minha Sè, quão diferente, da Sè velha te ves, agora, e viste!

Tu muy alegre estas, ella muy triste;

ella com bem pezar, tu bem contente;

A ti fertilizou-te a grossa enchente daquelle braço, a que ninguém resiste; a ella deulhe à breca, em que consiste ficar de pé quebrado, e descontente:

Teus cônegos, jà são participantes dos bens, que quem lhos deu, também os dera aos outros, se os achàra semelhantes.

Mas estes formão cà tam Primavera, que vemos a Capella, que era dantes, crescer mais, que a Sè, que dantes era.

SONETO ATRIBUÍDO A GREGÓRIO DE MATOS E GUERRA, OBRA POÉTICA, 2013, VOL. 3, P. 32

Pondo os olhos primeiramente na sua cidade conhece, que os Mercadores são o primeiro móvel da ruína, em que arde pelas mercadorias inúteis, e enganosas.

Soneto 4

Triste Bahia! Ó quão dessemelhante

Estás, e estou do nosso antigo estado!

Pobre te vejo a ti, tu a mim empenhado, 
Rica te vejo eu já, tu a mim abundante.

A ti tocou-te a máquina mercante, Que em tua larga barra tem entrado, A mim foi-me trocando, e tem trocado Tanto negócio, e tanto negociante.

Deste em dar tanto açúcar excelente Pelas drogas inúteis, que abelhuda Simples aceitas do sagaz Brichote.

Ó se quisera Deus, que de repente Um dia amanhecera tão sisuda Que fora de algodão o teu capote!

SONETO ATRIBUÍDO A FRANCISCO RODRIGUES LOBO, FÊNIX RENASCIDA, VOL. I, P. 143

Fermoso Tejo meu, quão differente Te vejo, e vi, me vês agora, e viste, Turvo te vejo a ti, tu a mim triste, Claro te vi eu já, tu a mim contente.

A ti foy-te trocando a grossa enchente A quem teu largo campo não resiste, A mim trocoume a vista, em que consiste O meu viver contente, ou descontente. Já que somos no mal participantes, Sejamolo no bem: oh quem me dera Que fossemos em tudo semelhantes!

Mas lá virá a fresca Primavera, Tu tornarás a ser quem eras de antes, Eu não sei se serey quem de antes era. 
Marcello Moreira é professor pleno de Historiografia e História Literária e de Letras Luso-Brasileiras do Departamento de Estudos Linguísticos e Literários da Universidade Estadual do Sudoeste da Bahia, UESB-DELL, Estrada do Bem Querer, Vitória da Conquista, Bahia. 